\title{
Military dentistry themed issue
}

Quentin Anderson

Guest Editor and Colonel Commandant, Royal Army Dental Corps, Regimental Headquarters, Surrey, UK.

The BDJ Upfront section includes editorials, letters, news, book reviews and interviews. Please direct your correspondence to the News Editor,

Kate Quinlan at k.quinlan@nature.com. Press releases or articles may be edited, and should include a colour photograph if possible.

I am honoured to have been asked to be guest editor of this military dentistry themed issue of the $B D J$ and would particularly like to thank all the friends and colleagues who have contributed to this issue as authors as well as those who have provided support, information and advice. In the centenary year of the Royal Army Dental Corps (RADC), it is interesting to note a $B D J$ editorial from 1921 which opens with: 'The formation of the Army Dental Corps is an event of the first importance.' ${ }^{1}$ From shortly after its incorporation in 1880, the British Dental Association had expressed concerns over the lack of an organised dental service for the Royal Navy and the Army, and had petitioned for the creation of effective dental services for the armed forces. The formation of the Royal Naval Dental Service and the Army Dental Corps in 1920 and 1921, respectively, was the culmination of nearly 40 years of campaigning. It is fitting, therefore, that the Association's journal should now be marking the Corps' centenary with this themed issue.

The range of articles selected for this issue are not the usual series of detailed clinical papers but rather a window on the last one hundred years, including some of the experiences of individual members of the Corps as well as current developments.

The term military dentistry immediately associates dentistry and the armed forces; however, what is less obvious is exactly what military dentistry's purpose is and what that involves. The article on defence dentistry gives insight to both these questions. The terms defence dentistry and military dentistry can be considered effectively synonymous, although in the context of this issue and its relation to the RADC's centenary, most articles present it from an Army perspective.

The aim of military dentistry is to improve oral health in order to mitigate the impact of dental morbidity on military operations. The inescapable corollary of this is the promotion, achievement and maintenance of good oral

health in the military population at risk. This is as true and relevant now as it was a hundred years ago.

Apart from kinetic injury due to enemy action and an increased potential for accidental trauma, the operational environment presents specific additional risks to the oral health of service personnel including the effects of stress, dehydration and diet. In addition, the development of a dental problem on deployment can have significant consequences. Many of the military population at risk (PAR) will not be co-located with a dental team. Access to care, therefore, presents both logistical problems and risk. Movement of casualties requires road

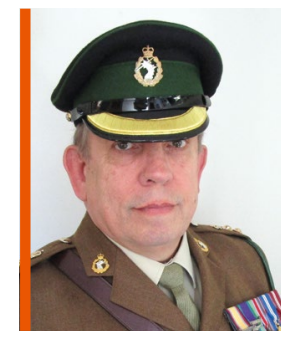

and/or air transport which, dependent on the prevailing military situation, presents a range of risks, particularly of enemy interdiction, to vehicles, their crew and the casualties. Time taken by a casualty away from their unit for treatment also leaves their unit understaffed and potentially at increased risk. Conversely, not evacuating a dental casualty could leave an individual in post who can no longer fully concentrate on their task and thus presents a risk both to themselves and their team.

While dental problems cannot be totally avoided, good pre-deployment oral health plays a significant role in minimising the prevalence and severity of dental morbidity in the field. In the occupationally-focused dental service provided to the armed forces, the uniformed dental team is in a privileged position; through military training and experience on exercises and operations, they have excellent insight into field conditions and their implications for oral health. They also understand individual patients' roles, locations and the corresponding risks presented by a dental problem in the field. Where relevant, this can be usefully incorporated into treatment decision making and allows a more informed, personalised patient discussion and consent process. RADC dental teams also not only share with their patients membership of the same organisation and the Army's values and standards, but also live, socialise, and play sport as integral members of their military community. This enhances their understanding of their specific PAR and can significantly benefit communications with both individual patients and their chain of command.

\section{'The aim of military dentistry is to improve oral health in order to mitigate the impact of dental morbidity on military operations'}

On deployment, a dental team's primary role is the prompt treatment and return to unit of dental casualties. This can sometimes be in austere or unusual circumstances. In addition, the prevailing situation may also call on them in a variety of other capacities - some planned and some unexpected!

For those of you with little or no military experience, I hope that you find this issue of interest as it casts a light on the work of an often unseen part of the profession. For former members of the Corps and its sister Services, perhaps it will evoke a wry smile of recognition as it triggers distant memories, as well as being of general interest in both past and current activities. Above all, I hope you enjoy reading it.

\section{References}

. Editorial. The Army Dental Corps. Br Dent J 1921; 42: 157-158.

https://doi.org/10.1038/s41415-021-2843-0 